\section{Metal-carbon mesocomposites application possibilities as the medicine magnetic transport within an organism}

\author{
VI Kodolov ${ }^{1,2 *}$, VV Kodolova-Chukhontseva ${ }^{1,3}$, IN Shabanova ${ }^{1,4}$ \\ and NS Terebova ${ }^{1,4}$
}

\author{
${ }^{1}$ Basic Research, High Educational Centre of Chemical Physics \& Mesoscopics, UD, RAS, \\ Izhevsk, Russia \\ ${ }^{2}$ MT Kalashnikov Izhevsk State University, Izhevsk, Russia \\ ${ }^{3}$ Peter the Great S tPetersburg State Polytechnic University, St Petersburg, Russia \\ ${ }^{4}$ Udmurt Federal Research Centre, Russian Academy of Science, Izhevsk, Russia
}

\begin{abstract}
More Information
*Address for Correspondence: VI Kodolov, MT Kalashnikov Izhevsk State University, Izhevsk, Russia Tel: +34-915 622 900; Fax: 3412-50-79-59; Email: vkodol.av@mail.ru

Submitted: 09 September 2020

Approved: 10 December 2020

Published: 11 December 2020

How to cite this article: Kodolov VI, Kodolova-Chukhontseva VV, Shabanova IN, Terebova NS. Metal-carbon mesocomposites application possibilities as the medicine magnetic transport within an organism. Int J Phys Res Appl. 2020; 3: 143-145.

DOI: 10.29328/journal.ijpra.1001032

Copyright: () 2020 Kodolov VI, et al. This is an open access article distributed under the Creative Commons Attribution License, which permits unrestricted use, distribution, and reproduction in any medium, provided the original work is properly cited.
\end{abstract}

A) Check for updates

\section{Abstract}

The paper is dedicated to the consideration of the metal-carbon mesocomposites application possibilities for the medicine magnetic transport. This trend is determined by correspondent peculiarities of content and structure of mesoscopic composites. The main peculiarities of these nanosized particles are the following: a) the presence of unpaired electrons on the carbon shell; b) the structure of carbon shell from poly acetylene and carbine fragments; c) the atomic magnetic moment of inner metal is equaled to more than 1-3 $\mu \mathrm{B}$. The creation of reactive mesoscopic materials with regulated magnetic characteristics which can find application as medicine magnetic transport within an organism is very topical. The present investigation has fundamental character. It's based on the ideas concerning to the change of metal-carbon mesocomposites reactivity. The use is possible as metal-carbon mesocomposites both and they are modified analogously.
OPEN ACCESS

\section{Introduction}

In the recent studies his great attention is spared to the creation of medicine remedies with address direction for the action on the organs that are needed in correspondent healing. Usually the transport of therapeutically active substances to the correspondent organ is carried out using the magnetic mesoparticles containing the linker connected with medicine substance. In other words, the remedies of medicine carriage in organisms are constructed on the following scheme: transport magnetic mesoparticle - linker - medicine [1]. In the above patents the iron-containing nanosized particles, for example, $\mathrm{Fe}_{3} \mathrm{O}_{4}$, is used as magnetic mesoparticle, and the organic substances are connected with this mesoparticle by covalent or coordinative bonds as linker. In this case it's possible the certain difficulties in the undoing of medicine because of the bio-active substances big interaction with some functional groups. The medicine release from magnetic mesoparticles with a linker occurs at the variable magnetic fields. It is well-known that the best linker can be phosphorus organic compounds that are easily destructed in water [2].

\section{Description mesoscopic-phosphorus-containing metal carbon composites}

Kodolov, et al. proposed [3] to accomplish the modification of metal containing magnetic mesoparticle by ammonium polyphosphate. At the same time the copper carbon mesocomposite [4] is suggested as a magnetic mesoparticle since the copper has bactericides' and anti-microbes properties and increases the organism's protective forces. For that reason, the copper carbon mesoscopic composite modified by ammonium polyphosphate chooses as the object of the investigations. The modification process is carried out by the mechanic chemical method in processing. The phosphorus reduction and the formation of the linker that contains phosphorus with the following oxidation states as $0,+3$, and +5 takes place.

The obtaining of remedy for medicine delivery to a definite organ is carried out on the following scheme:

The phosphorus containing copper carbon mesoscopic 
composites $\left(\mathrm{MC}_{(\mathrm{P} \mathrm{P}}\right)$ are applied as magnetic mesoparticles. Then the medicines $(\mathrm{M})$ are linked with $\mathrm{MC}_{(\mathrm{P})}$ at the relation $\left(\mathrm{MC}_{(\mathrm{P})} / \mathrm{M}\right)$ correspondent to $1:(0,02-0,5)$ using the mechanic chemical method with the application of the mechanical mortar. The $\mathrm{MC}_{(\mathrm{P})}$ applied is obtained by the interaction of copper carbon mesocomposite ( $\mathrm{Cu}-\mathrm{C} \mathrm{MC}$ ) and ammonium polyphosphate (APP) at the relation 1:0,5 for the obtaining of high atomic magnetic moment of copper. The therapeutically active substances such as adenosine tri phosphorus acid (the relation $\left.\mathrm{MC}_{(\mathrm{P})} / \mathrm{M}=1: 0,02\right)$, ascorbic acid $\left(\mathrm{MC}_{(\mathrm{P})} / \mathrm{M}=1: 0,2\right)$ and Urotropine $\left(\mathrm{MC}_{(\mathrm{P})} / \mathrm{M}=1: 0,5\right)$ is linked with phosphorus containing mesocomposite across the phosphorus containing linker.

The investigations of phosphorus containing copper carbon mesocomposite and its analogous are realized with the application of methods complex [5]. The basic methods are: the X-ray photoelectron spectroscopy (RPES), transition electron microscopy of high solution (permeation) (TEM), electron micro diffraction, electron paramagnetic resonance (EPR), and the X-ray diffraction measuring.

According to these investigations the copper atomic magnetic moment growth is established at the copper carbon mesocomposite modification by ammonium polyphosphate and therapeutically active substances. The atomic magnetic moment of copper is obtained more $\left(\mu=4,5 \mu_{\mathrm{b}}\right)$ in the comparison with iron containing nanostructures $\left(\mu=2,5 \mu_{\mathrm{b}}\right)$. Hence the proposed magnetic mesoparticles can be interested as the remedies of medicine carriage in organisms using drive magnetic field.

The production of magnetic mesoscopic particles with connected therapeutically active substances is realized by mechanic chemical method on the next scheme:

- The reduction-oxidation synthesis of copper carbon mesocomposite from $\mathrm{CuO}$ and polyvinyl alcohol at the reagents relation equaled to $1 \mathrm{~mol}: 4 \mathrm{~mol}$ [4].

- The copper carbon mesocomposite modification by ammonium polyphosphate at the reagents relation $[6,7]$.

- The phosphorus-containing copper carbon mesocomposite modification by therapeutically active substances, such, as adenosine tri phosphoric acid (relation - 1:0,02), ascorbic acid (relation - 1:0,2) and Urotropine (relation - 1:0,5). (Pat. 2018143197).

The mechanic chemical synthesis is carried out with the using of mechanical mortar by the joint grinding of reagents at the energetic expenses approximately equaled to 260-270 $\mathrm{kJ} / \mathrm{mol}$. After the mechanic chemical process, the mesoscopic product obtained is dried in the closed crucible at $400^{\circ} \mathrm{C}$ for the first stage, and at $150^{\circ} \mathrm{C}$ for second and third stages. Then the product obtained is standee in vacuum at $100-150^{\circ} \mathrm{C}$ for 3 minutes.
The results of the mechanic chemical process with thermo chemical finishing are estimated with the application of the following methods: X-ray photoelectron spectroscopy, electron paramagnetic resonance, transition electron microscopy with high permission.

The transition analytic electron microscope FET Tecnai G2F20 with prefix EDAX is used for the investigation of copper carbon mesoscopic composite structure and phase content. High permission corresponds to $2 \mathrm{~nm}$ in $1,5 \mathrm{~cm}$.

$\mathrm{X}$-ray photoelectron spectroscopic investigations are realized by X-ray photoelectron magnetic spectrometer with the permission $10^{-4}$ at the activation $\mathrm{AlK}_{\alpha}$ line $1486 \mathrm{eV}$ in vacuum $10^{-8}-10^{-10}$ Torre. Based on Van Fleck theory, the model for metal atomic magnetic moments calculation is proposed.

EPR investigations are carried out by means of EPR spectrometer E-3 of firm «Varian».

The peak correspondent to binding energy 132,5 $\mathrm{eV}$ is ascribed [8] bond $\mathrm{C}=\mathrm{P}$ that can be possible at the appearance of interference phenomenon because of the direct electromagnetic field which arises at annihilation in red-ox process. The unpaired electrons presence on the carbon shell of mesocomposite can promote the decreasing of free radical activity in the defeat part of the organism. The high atomic magnetic moment of Copper (more than $4 \mu_{\mathrm{B}}$ ) can be used for the address carriage of medicine.

Thus, the transport remedy included the copper carbon mesocomposite and linker containing phosphorus for the connection therapeutically active substances is proposed.

The investigations of medicines modified by the above magnetic mesocomposites are carried out with the application of X-ray photoelectron spectroscopy. Below C1s spectra for these medicines are presented (Figure 1).

The discussion of the electron structures changes for the modified bio active substances takes place below in following order:.1) ATP; 2) AA; and 3) U.

After the modification of phosphorus-containing copper carbon mesocomposite, obtained at the relation $\mathrm{Cu}-\mathrm{C} \mathrm{MC} /$ APP equaled to 2, by adenosine tri phosphorus acid (relation "1:0,02") the following changes of the mesoparticle surface structure takes place:

- In $\mathrm{C} 1 \mathrm{~s}$ spectrum the maximum for $\mathrm{C}-\mathrm{H}$ bond is considerably increased;

- In this spectrum the appearance of new content at $283 \mathrm{eV}$ correspondent to sp hybridization, and the maximum for $\mathrm{sp}^{2}(\mathrm{C}-\mathrm{C})$ and also $\mathrm{sp}^{3}(\mathrm{C}-\mathrm{C})$ hybridization are decreased;

- In C1s spectrum new maximum $(286,7 \mathrm{eV})$ for $\mathrm{C}-\mathrm{N}$ bond is observed; 


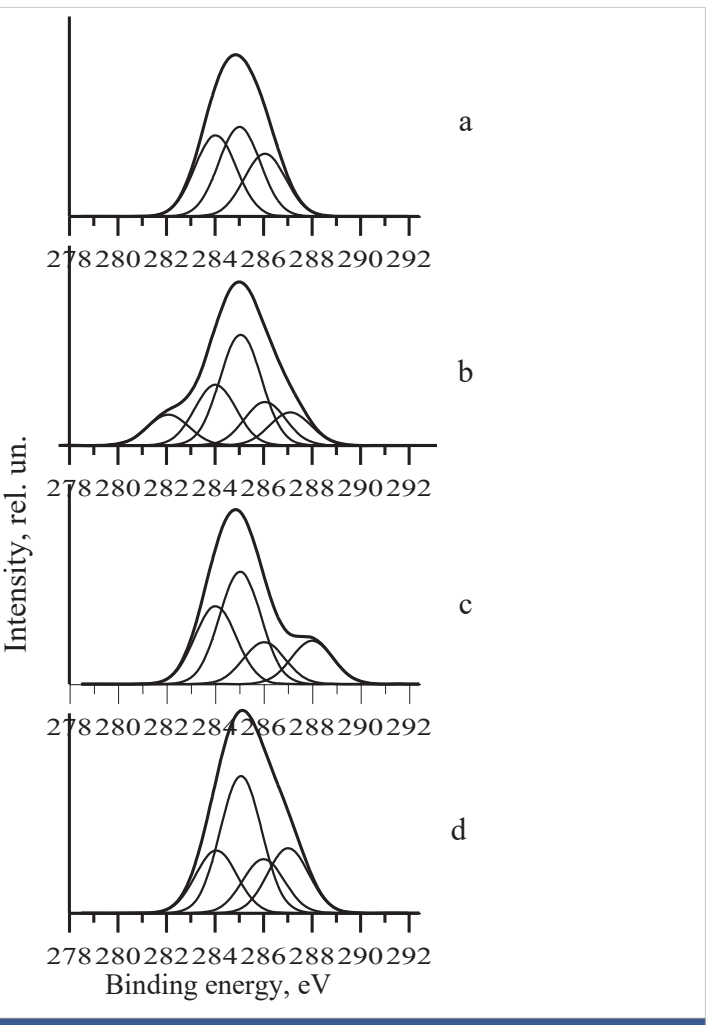

Figure 1: C1s spectra phosphorus containing copper carbon mesocomposite (a) and its analogous modified adenosine tri phosphorus acid (relation "1:0,02") (b) ascorbic acid (relation "1:0,2") (c), Urotropine (relation "1:0,5") (d).

- In $\mathrm{Cu} 2 \mathrm{p}$ and $\mathrm{P} 2 \mathrm{p}$ spectra the peaks for $\mathrm{Cu}-\mathrm{P}$ and $\mathrm{Cu}-$ $\mathrm{P}-\mathrm{O}$ are found.

It's necessary to note that the magnetic moment determined on $\mathrm{Cu} 3 \mathrm{~s}$ spectrum did not exchange and is equaled to $4,5 \mu_{\mathrm{B}}$.

The above changes in spectra can be explained by the carbon phosphorus shell deformation at the interaction of adenosine tri phosphorus acid with transport remedy.

In the X-ray photoelectron spectra of mesoparticles obtained using the phosphorus containing mesocomposite modification by ascorbic acid at the reagents relation 1:0,2 the following changes are discovered:

- In C1s spectrum in comparison on the spectrum of initial mesocomposite the new maximum $\left(\mathrm{E}_{\mathrm{b}}=288 \mathrm{eV}\right)$ for $\mathrm{C}-\mathrm{OH}$ group is present;

- In $\mathrm{Cu} 2 \mathrm{p}$ and $\mathrm{P} 2 \mathrm{p}$ spectra the maximums for $\mathrm{Cu}-\mathrm{P}, \mathrm{Cu}-\mathrm{O}$ and $\mathrm{P}-\mathrm{O}$ bonds are observed.

The magnetic moment determined on Cu3s spectrum also as in above example is not changed and equaled to $4,5 \mu_{B}[9,10]$.

The changes in x-ray photoelectron spectra of phosphorus containing $\mathrm{Cu}-\mathrm{C}$ mesocomposite modified by Urotropine at the relation 1:0,5 also take place. Below the following peculiarities in spectra are given:
- In the $\mathrm{C} 1 \mathrm{~s}$ spectrum the $\mathrm{C}-\mathrm{H}$ maximum increasing is found;

- In the same spectrum the maximum for $\mathrm{C}-\mathrm{N}$ bond $\left(\mathrm{E}_{\mathrm{b}}\right.$ $=287 \mathrm{eV}$ ) appears, and the maximums attributed to $\mathrm{sp}^{2}$ and $\mathrm{sp}^{3}$ hybridization have near intensity;

- In P2p spectrum the maximums at $135 \mathrm{eV}\left(\mathrm{P}^{+5}\right)$ and 129 $\mathrm{eV}\left(\mathrm{P}^{0}\right)$ take place.

- In the N1s spectrum the covalent bond $\mathrm{C}-\mathrm{N}$ is determined.

In this case the copper atomic magnetic moment is near to $4,5 \mu_{\mathrm{B}}$.

It's interest to note that the carbine component (sp hybridization) is observed at the mesocomposite quantity increasing.

\section{Conclusion}

Thus, the above mentioned examples show the connection of therapeutically active substances with transport remedy (phosphorus-containing copper carbon mesocomposite) at the conservation of magnetic properties. Latter is necessary for the application of the obtained substances in practice.

\section{References}

1. Pat. RU N 2490027, 2017.

2. Gefter EL. Phosphorus organic monomers and polymers. M. Acad Sci. 1960; 288.

3. Kodolov VI, Trineeva VV, Terebova NS. et al. The change of electron structure and magnetic characteristics of modified copper carbon na nocomposites.//Chemical Physics \& Mesoscopics. 2018; 20: 72-79.

4. Kodolov VI. Shabanova IN, Kodolova-Chukhonzeva VV, Terebova NS, Pershin YV, et al. Modified magnetic metal carbon mesoscopic composites with bioactive substances. Chemical Physics \& Mesoscopics. 2019; 21: 446- 454.

5. Kodolov VI, Trineeva VV, Pershin YV. et al. Method of metal carbon nanocomposites obtaining from metal oxides and polyvinyl alcohol. Pat. RU 2018122 001, 2020.

6. Kodolov VI, Trineeva V.V., Kopylova AA. et al. Mechanochemical modification of metal carbon nanocomposites. Chemical Physics \& Mesoscopics. 2017; 19: 569-580.

7. Mustakimov RV. The method of modification of metal carbon nanostructures by ammonium poly phosphate. Pat. N 2694092. 2019

8. Wang JQ, Wu WM, Feng DM. The introduction of Electron Spectroscopy (XPS/XAES/UPS). Beijing: National Definite Industry Press. 1992; 640.

9. Kodolov VI, Semakina NV, Trineeva VV. Introduction in science about nanomaterials. Monograph. Izhevsk: Publisher MT. Kalashnikov Izhevsk State Technical University. 2018; 476.

10. Kodolov VI, Kodolova-Chukhontseva VV. Fundamentals of Chemical Mesoscopics. Monograph. Izhevsk: Publisher MT. Kalashnikov Izhevsk State Technical University. 2019; 218. 